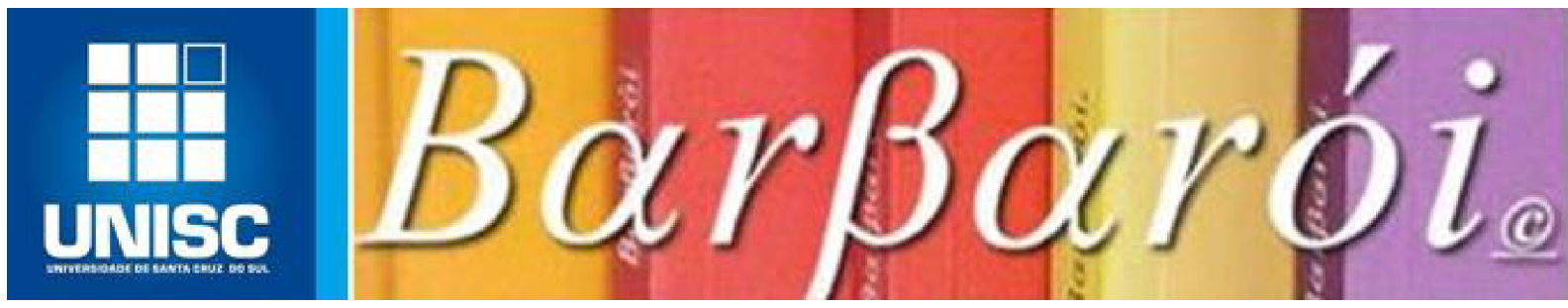

\title{
O SERVIÇO SOCIAL NA UNIVERSIDADE COMUNITÁRIA DE SANTA CRUZ DO SUL: ASPECTOS HISTÓRICOS E ATUAIS DA FORMAÇÃO
}

DOI: http://dx.doi.org/10.17058/barbaroi.v0i59.16986

\author{
Eunice Maria Viccari \\ Universidade de Santa Cruz do Sul - UNISC - Brasil \\ Maira Meira Pinto \\ Universidade de Santa Cruz do Sul-UNISC-Brasil \\ Marta von Dentz \\ Universidade de Santa Cruz do Sul - UNISC - Brasil
}

\section{Resumo:}

O presente artigo apresenta a história do Curso de Serviço Social da UNISC, que está completando vinte anos de existência, além de tecer articulações com a formação em Serviço Social na contemporaneidade. Entendemos que construir uma abordagem sobre a historicidade formativa do Serviço Social nesta instituição de ensino superior, implica realizar um aprofundamento daquilo que o Serviço Social possui de acúmulo, de trajetória, de experiência, tecendo articulações acerca da formação em Serviço Social. Para tanto, organizamos este itinerário em três momentos: primeiro, buscamos mobilizar a memória da qual o momento atual do Curso de Serviço Social da Unisc é herdeiro, enfatizando sua trajetória histórica, sua gênese, seus desafios, os profissionais formados pelo curso, as pesquisas de Trabalho de Conclusão de Curso realizadas, os docentes envolvidos neste percurso de praticamente duas décadas; em seguida, focalizamos na formação, nos Projetos Político Pedagógicos que fizeram parte desta história e nos campos de estágio; e, por fim, argumentamos acerca das contribuições do Curso de Serviço Social para o contexto regional, com base nos projetos de extensão e nas pesquisas realizadas. Como sintetizações, reiteramos as diferentes contribuições do Curso de Serviço Social, durante vinte anos, em âmbito local e regional, por intermédio da formação de inúmeros acadêmicos, de projetos interventivos, de pesquisas, de projetos de extensão que incidiram diretamente nas diferentes realidades sociais. 
Palavras-chave: Serviço Social; Ensino Superior; Formação.

\section{Introdução}

"Pareceu-me que nesses tempos de incertezas, em que o passado se esquiva e o futuro é indeterminado, seria preciso mobilizar nossa memória para tentar compreender o presente" (CASTEL, 1998, p. 21).

Uma breve incursão nos aportes teóricos do sociólogo Robert Castel possibilita tecer argumentações iniciais, neste artigo, no que se refere ao exercício de "mobilizar a memória" em tempos de incertezas. Para além de mencionar afrescos do passado numa dimensão saudosista, a epígrafe supracitada provoca a apreensão do caráter aleatório em que se configura o presente, aquilo que acontece hit et nunc (CASTEL, 1998). Ao mobilizar esses elementos, o que se objetiva é tecer articulações com a formação em Serviço Social na contemporaneidade e, mais especificamente, à trajetória histórico-formativa do Curso de Serviço Social da Universidade de Santa Cruz do Sul (Unisc).

Neste sentido, construir uma abordagem sobre a historicidade formativa do Serviço Social nesta instituição de ensino superior, implica realizar um aprofundamento daquilo que o Serviço Social possui de acúmulo, de trajetória, de experiência. Este empenho, de compreender o presente, de mobilizar a memória, possibilita reconstruir uma história da qual o momento presente é herdeiro. Um efeito de herança, sendo que a memória de tal herança é necessária para compreender e agir no hoje (CASTEL, 1998, p. 23).

Importante destacar que esta elaboração faz parte de um momento histórico mais amplo vivido pela Universidade de Santa Cruz do Sul como um todo e pelo Departamento de Ciências Humanas, onde o Curso de Serviço Social se vincula institucionalmente desde sua gênese. Este momento histórico é denominado como "Reinvenção", que se amplifica desde o repensar da estrutura organizacional da Universidade até os Projetos Político Pedagógicos dos Cursos. Em outras palavras, desde os anos 2000 - início do curso de Serviço Social - o mesmo fez parte do Departamento de Ciências Humanas. E, neste ano de 2019, a partir deste processo de reinvenção, os departamentos como um todo na Universidade se modificam e o Departamento ao qual o Curso se vinculará a partir de 2020 terá nova composição, não mais como Ciências Humanas (sociólogos, filósofos, antropólogos, assistentes sociais), mas, sim, como Ciências Humanidades e Educação.

A partir destes aportes e esclarecimentos introdutórios retomamos a objetividade deste estudo, a saber: tecer articulações acerca da formação em Serviço Social e, mais especificamente, da trajetória histórico-formativa do Curso de Serviço Social no âmbito 
regional da Universidade de Santa Cruz do Sul. Para tanto, organizamos este itinerário em três momentos: primeiramente buscamos mobilizar a memória da qual o momento atual do Curso de Serviço Social da Unisc é herdeiro, enfatizando sua trajetória histórica, sua gênese, seus desafios, os profissionais formados pelo Curso, as pesquisas de Trabalho de Conclusão de Curso realizadas e os docentes envolvidos neste percurso de praticamente duas décadas; como segunda ênfase, focalizamos na formação, nos Projetos Político Pedagógicos que fizeram parte desta história e nos campos de estágio; e, por fim, como terceiro elemento, argumentamos acerca das contribuições do Curso de Serviço Social para o contexto regional em que está inserido com base nos projetos de extensão e nas pesquisas realizadas.

\section{A Trajetória Histórica do Curso de Serviço Social na UNISC: memórias e desafios}

Destacamos, inicialmente, que a trajetória histórica do Curso em tela é parte de uma Instituição Comunitária que busca atender as demandas regionais desde a sua origem, 1962, quando a Associação Pró-Ensino em Santa Cruz do Sul (APESC), mantenedora da Universidade, foi fundada. Especificamente no que se refere ao Serviço Social, convém ressaltar que, em pesquisa realizada pela Universidade de Santa Cruz do Sul junto a comunidade de abrangência no final dos anos 1990, foi verificado que aquele Curso consistia na terceira maior demanda da região. Demanda que se manifestou em decorrência de uma conjuntura nacional, regional e local, de grandes transformações no âmbito do trabalho, determinada por uma crise política, econômica e técnica em que os processos de globalização, informatização e reestruturação da produção acentuaram as vulnerabilidades e os riscos sociais a que a população é afeta.

Neste contexto, contraditoriamente, vivia-se uma reforma do Estado, enquanto simultaneamente estruturas de políticas sociais necessárias estavam sendo implantadas diante das premissas de descentralização política e administrativa, requerendo, portanto, trabalhadores sociais, entre eles assistentes sociais. Convém ressaltar que os profissionais formados em Serviço Social trabalham diretamente com políticas sociais públicas e com as determinações da Questão Social e suas múltiplas expressões (CARVALHO; IAMAMOTO, 1983).

Continuamente, para abordar aspectos específicos do Curso de Serviço Social na Unisc, ressaltamos que o mesmo teve início na Instituição no ano de 2000, integrando o Departamento de Ciências Humanas, juntamente com o Curso de Filosofia. A oferta do Curso, na época, respondeu as seguintes demandas: a natureza comunitária da Instituição que atua no âmbito das demandas sociais regionais; a não existência de Curso de Serviço Social 
nas regiões dos Vales do Rio Pardo e Taquari; o interesse pelo Curso de Serviço Social constatado por levantamento feito junto a vestibulandos de 1996 a 1998; e o fato de todos os assistentes sociais atuantes na região terem se graduado em municípios distantes, especialmente na grande Porto Alegre ${ }^{1}$.

Tendo em vista as demandas supracitadas, o Curso de Serviço Social foi, então, cotejado e requisitado a compor o arcabouço formativo da Unisc. Para implantar o Curso, foi instituída uma comissão de trabalho. Esta comissão foi integrada pela professora, nomeada para coordená-lo, Sarita Amaro, e Isabel Zanetti - ambas assistentes sociais - e um representante da área pedagógica da Pró-Reitoria de Graduação da Universidade. Para compor esta equipe a Universidade pensou em uma profissional da área e que estivesse presente na região (Sarita Amaro), bem como uma profissional atuante no município de Santa Cruz do Sul (Isabel Zanetti, que na época atuava junto ao Poder Judiciário da comarca local).

Em sua trajetória histórico-formativa o Curso totaliza, em 2019, duzentos e noventa (290) profissionais assistentes sociais formados pela Instituição. Podemos visualizar este quantitativo anualmente no gráfico 1.

\section{Gráfico 1: Quantitativo de acadêmicos concluintes por ano (2000-2019) no Serviço} Social da UNISC

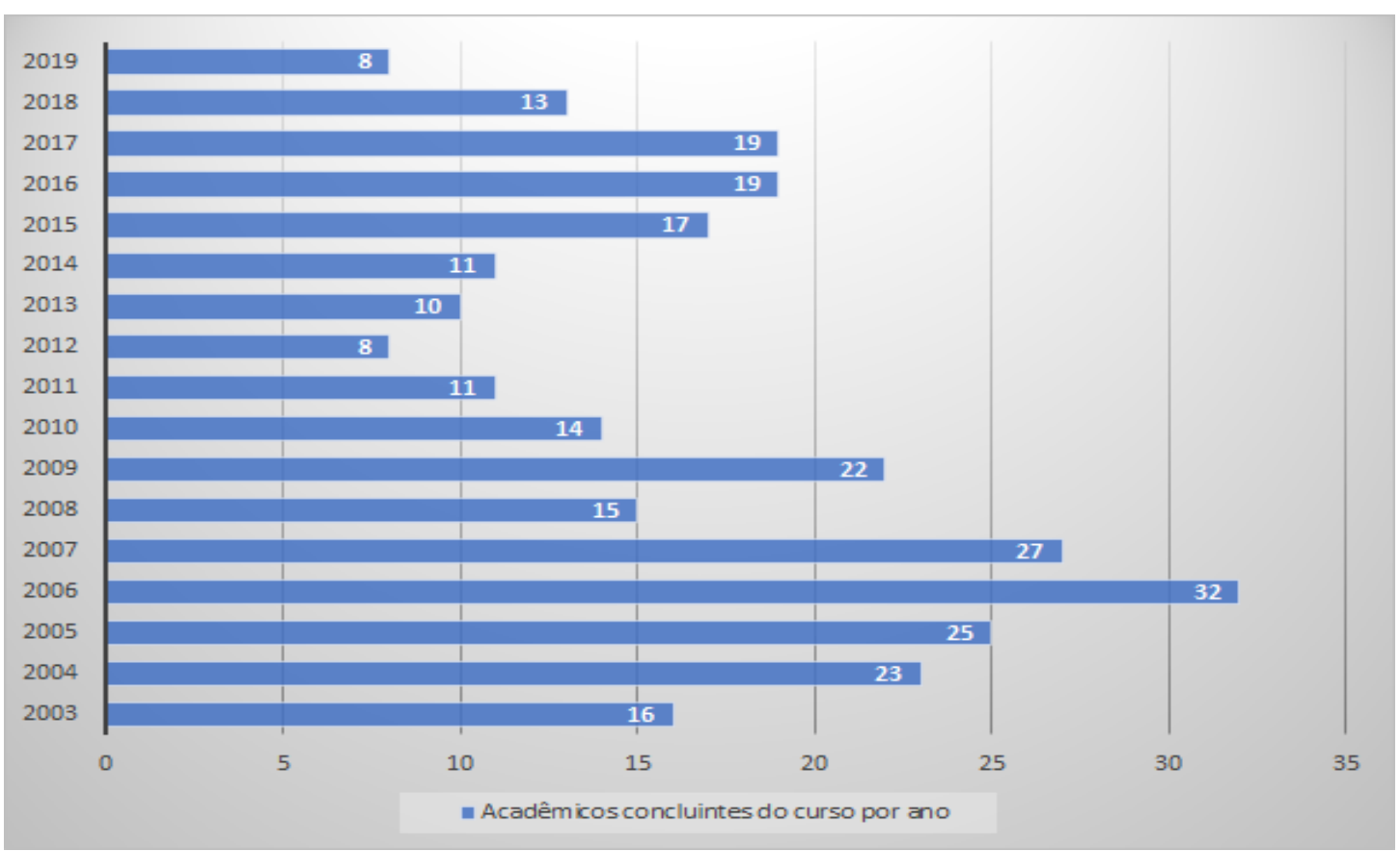

Fonte: As autoras (2019).

\footnotetext{
${ }^{1}$ Estas informações constam no Projeto Político Pedagógico do Curso (2018).
} 
Consideramos que, durante estas duas décadas de trajetória, as demandas que referenciaram a formação de profissionais na área do Serviço Social na região se alteraram. A existência do Curso de Serviço Social nas regiões dos Vales do Rio Pardo e Taquari continua formando profissionais para atuarem em diferentes espaços e, muito além de sanar uma demanda regional por este profissional, a formação ganha, atualmente, maior amplitude. Os profissionais formados na Unisc atuam em diferentes frentes e espaços sociocupacionais, buscando garantir direitos humanos e sociais em diferentes locais que operacionalizam políticas sociais públicas e em outras instâncias organizacionais. Destacamos que, na época dos anos 2000, a Unisc era a única instituição a oferecer o Curso na região. Este cenário foi se alterando paulatinamente, sobretudo com a entrada da modalidade de ensino à distância, modalidade na qual o Curso passou a ser ofertado por diferentes instituições que adentraram na região.

Vejamos que esta peculiaridade da formação em Serviço Social presencial nesta Instituição encontra desafios muito mais complexos e profundos. Em âmbito nacional temos dados importantes datados de 2012.

\begin{abstract}
A formação em Serviço Social [...] dispõe de diretrizes curriculares nacionais para o ensino de graduação propostas por nossas entidades representativas (Abess/Cedepss, 1996), aprovadas e reguladas pelo Estado. Elas norteiam os 567 cursos de graduação autorizados em agosto de 2012,518 dos quais são privados $(91,4 \%)$ e 49 , públicos $(8,6 \%)$. Os 230 cursos à distância são exclusivamente privados e correspondem a $44,4 \%$ do conjunto dos cursos privados, enquanto os presenciais somam 288 , ou seja, 55,6\% dos cursos privados (IAMAMOTO, 2017, p. 20).
\end{abstract}

Em âmbito estadual, em levantamento realizado em 2017, o Estado do Rio Grande do Sul contava com quatorze (14) instituições de ensino superior ofertando o curso de Serviço Social presencial na iniciativa privada; três (3) instituições em âmbito federal e quinze (15) instituições privadas na modalidade à distância. O levantamento reafirma, de maneira detalhada, a predominância histórica do ensino superior privado no Estado em tela e ausência histórica do ensino federal em Serviço Social, criado apenas em 2006 e se expandindo até 2010. Ademais, informa sobre a crescente oferta do ensino privado na modalidade à distância e a ausência completa do ensino em âmbito estadual (DENTZ, 2017). Em âmbito local, a Reitoria da Universidade de Santa Cruz do Sul tem realizado permanente levantamento e, em 2019, somente no município de Santa Cruz do Sul, foram identificadas mais de trinta (30) instituições ofertando ensino superior. Dentre estas instituições algumas ofertam o ensino em Serviço Social na modalidade à distância.

A ampliação da perspectiva da mercantilização do Ensino Superior, a perspectiva do aprendizado ao longo da vida que, no limite, tem instigado a busca pela formação rápida e 
moldada ao tempo disponível da vida das pessoas, dentre outros aspectos que o leitor pode pensar (PEREIRA, 2009), tem provocado permanentemente o Curso de Serviço Social presencial da Unisc, sobretudo na atualidade, a repensar a formação, a ressignificar seu Projeto Político Pedagógico, e a dialogar abertamente com egressos e com a comunidade. Enfim, a reinventar-se.

Realizadas estas problematizações mais amplas, seguimos trazendo elementos constitutivos e históricos do Curso. Importante salientar que, durante as duas décadas de existência, as pesquisas realizadas pelos estudantes - nos Trabalho de Conclusão de Curso trouxeram contribuições, aprofundamentos, cientificidade ao processo formativo e às realidade sociais em que os mesmos tiveram contato, e desenvolveram seus projetos formativos. A contribuição dessas duzentas e noventa (290) pesquisas, em sua grande maioria, contemplaram os campos de estágio, os equipamentos em que os estudantes experimentaram e vivenciaram as aproximações com a profissão e, logicamente, questionaram e problematizaram elementos da vida social. Essas temáticas representam aprofundamentos teóricos, conhecimento e adensamento formativo. Ainda, representam contribuição para a comunidade local e regional, uma vez que discutem temas importantes e emergentes. 


\section{Gráfico 2: Temáticas pesquisadas nos Trabalhos de Conclusão de Curso em Serviço}

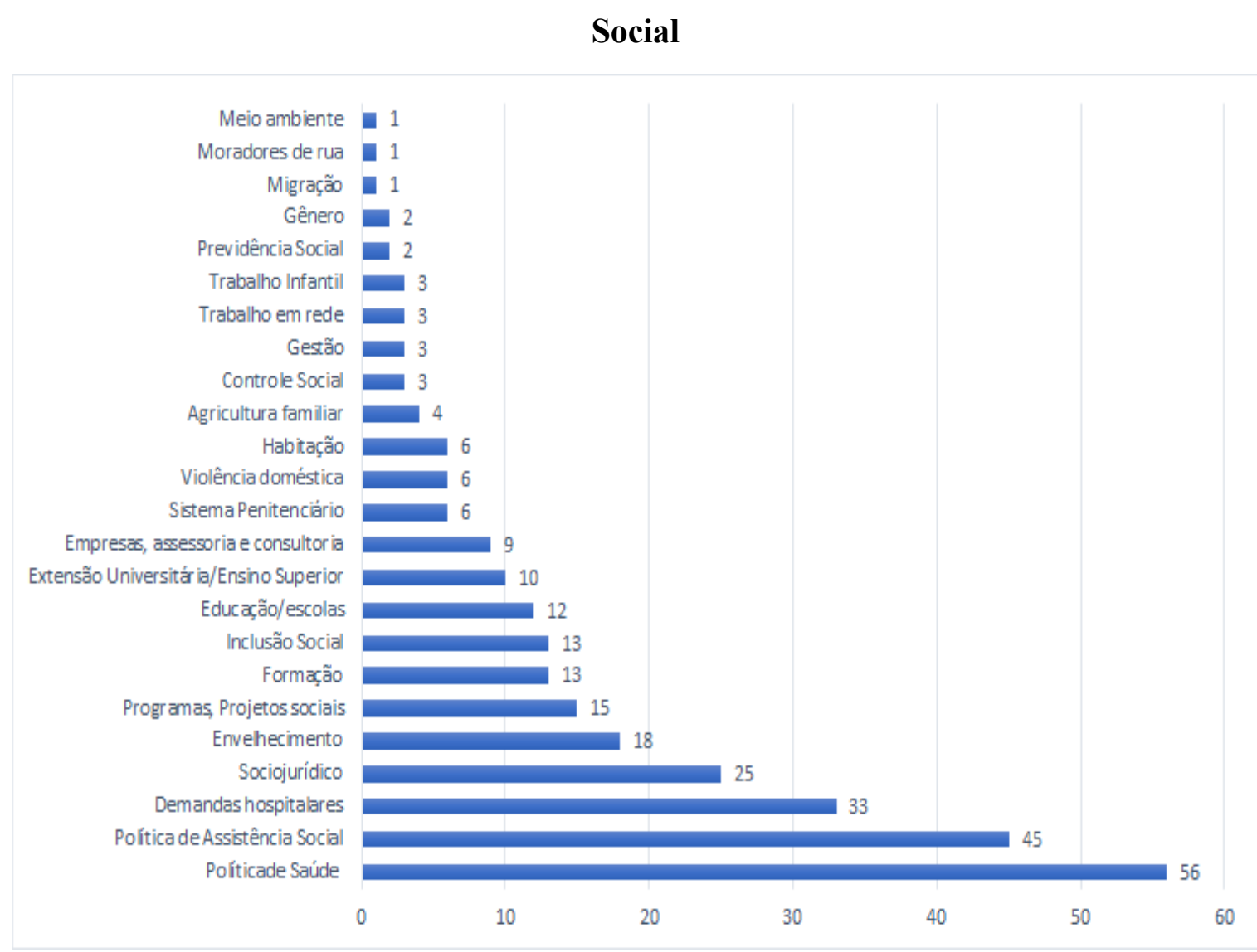

Fonte: As autoras (2019)

Notamos que a área temática com maior desenvolvimento de pesquisas ao longo da história do Curso foi a da saúde. Se somarmos a temática da saúde com a temática das demandas hospitalares temos um quantitativo de oitenta e nove (89) Trabalhos de Conclusão de Curso realizados. Portanto, a tônica histórica dos trabalhos conclusivos da formação considerou este campo com toda a sua diversidade. Neste eixo tivemos pesquisas voltadas para saúde mental, dependência química, estratégias de saúde da família, matriciamento, política pública de saúde, demandas da realidade hospitalar, pronto atendimento, gestantes, adolescentes gestantes, idosos em situação de abandono no espaço hospitalar, dentre outras. Como segunda maior temática pesquisada na história do Curso temos a Política de Assistência Social, seguida da área sociojurídica.

Importante destacar a presença das/os assistentes sociais docentes que fizeram parte da história do Curso. Composto fundamentalmente por mulheres, o corpo docente do Curso teve em seus primeiros anos de existência as seguintes profissionais atuando: Sarita Amaro, Joice Farina de Liz, Rosa Maria Castilhos Fernandes, Lea Maria Ferraro Biasi, Isabel Teresinha Zanetti, Claudia Hockheim Oliveira, Eunice Maria Viccari, Mirian L.Giglio Neves da Silva, 
Maira Meira Pinto, Isabel Cristina Velasques Stoelben, Jacqueline Rosa Pereira, Margarete Alessandrini, Maria Cristina S. Aguiar, Simone Ritta dos Santos e Caroline Goerck. A partir de 2006, outros profissionais enriqueceram esta história com suas contribuições profissionais: Christiane Carvalho Catarino Kurylo, Tatiana Reidel, Rosângela da Silva Almeida, Maria Madalena Marques, Cíntia Ribes Pestano, Edla Hoffman, Guiomar da Silva, Andrea Cristine de Lima, Antônio Carlos Gomes, Erika Scheeren Soares, Rosane Bernardete Brochier Kist e Marta von Dentz. Todos esses profissionais, assistentes sociais docentes, contribuíram com a construção desta história e a qualificação permanente do Curso.

Realizados esses aprofundamentos, seguimos trazendo especificidades importantes no que se refere à formação em Serviço Social realizada no percurso histórico do Curso em questão.

\section{A Formação em Serviço Social na UNISC: duas décadas de experiências}

Recordamos que focalizamos este momento nos aspectos formativos, especificamente, nos Projetos Político Pedagógicos que fizeram parte da história do Curso e nos campos de estágio. Este último, articulando permanentemente profissionais orientadores acadêmicos, supervisores de campo e estudantes em estágio.

De imediato, mencionamos que, durante as quase duas décadas de história, o Curso de Serviço Social da Unisc passou por sete (07) reformulações curriculares, sendo que a sétima revisão compõe o momento atual do Curso e de toda Universidade, o que chamamos anteriormente de "processo de reinvenção". De modo que, por tratar-se de um curso que forma profissionais que trabalham diretamente com demandas decorrentes das transformações societárias, o mesmo, através de seu corpo docente e do núcleo docente estruturante (NDE), promove um monitoramento constante, implicando em revisões no seu projeto político pedagógico e, por conseguinte, no seu currículo. A primeira revisão ocorreu após a formação de sua primeira turma, com implantação em 2005.

Em 2008 foi feita outra revisão curricular, atendendo às novas determinações do Ministério da Educação (MEC), presentes na resolução n.2, de 18 de junho de 2007, que estabelece como carga horária mínima 3.000 horas para o Curso de Serviço Social. Assim, a duração do Curso passou a ser de 3.000 horas, redução que representou a exclusão de 3 disciplinas do Núcleo de Fundamentos Teóricos-Metodológicos da Vida Social, inclusão de mais uma disciplina no Núcleo de Fundamentos do Trabalho Profissional e reorganização de 
carga horária em 7 outras disciplinas desse mesmo núcleo ${ }^{2}$. Essas alterações deram novo enfoque ao currículo e potencializaram o viés da formação profissional específica.

Ao final de 2010 a semestralização do Curso foi revista, adaptando-se a recomendações do MEC, ampliando a carga horária das disciplinas de estágio curricular obrigatório e de seus respectivos pré-requisitos. Como complementação a este ajuste, o corpo docente apresentou para avaliação das instâncias superiores da Universidade uma proposta de reorganização de disciplinas nos semestres, adequando a oferta de algumas à ênfase de cada nível de estágio, com vigência a partir do início de 2011. Em 2014 o Curso passou por reformulação curricular principalmente no que tange às atividades complementares. Em 2018 o Projeto do Curso foi repensado também, todavia, não efetivado operacionalmente. E uma nova revisão está sendo elaborada no momento atual consoante à "reinvenção pedagógica" da Unisc.

No primeiro currículo, que tinha 2700 horas, existia um enfoque em administração, planejamento e gestão. Constituiu-se num híbrido entre o currículo atual da época e o anterior, quando as diretrizes curriculares ainda não haviam sido implantadas. Chama atenção a disciplina de psicopatologia geral incluída no núcleo da vida social. De um modo geral, o currículo tece articulações entre políticas sociais, processos de trabalho e prática profissional e seminários temáticos. Na segunda versão, com 3240 horas, podemos verificar a tônica e o enfoque para as diferentes políticas sociais. Nesta versão, verificamos um currículo voltado exclusivamente para a compreensão e atuação nas diferentes políticas sociais, perspectiva curricular que estabeleceu uma linha contínua nas versões três, quatro e cinco, todas com 3000 horas, com pequenas alterações entre elas.

Importante ressaltar que, a partir da versão seis (2018), também com 3000 horas, o currículo passou a ser pensado de forma modular. Com maior abertura para a interdisciplinaridade, conteúdos articulados, bem como abertura de ênfases para áreas de sociologia, antropologia, filosofia e psicologia. Consideramos que inicia, com esta reformulação curricular, um processo pedagógico no Curso que estimula a ampliação do espectro da construção do conhecimento de forma dinâmica, interdisciplinar e inovadora. Cabe externalizar que a organização de módulos específicos da área profissional possibilita

\footnotetext{
${ }^{2}$ As Diretrizes Curriculares da ABEPSS de 1996 apontam para uma nova lógica curricular, que articula três Núcleos de Fundamentos, os quais traduzem um conjunto de conhecimentos constitutivos da formação profissional. 1. Núcleo de fundamentos teórico-metodológico da vida social; 2. Núcleo de fundamentos da formação sócio-histórica da sociedade brasileira; 3. Núcleo de fundamentos do trabalho profissional. Tais núcleos se tornam eixos articuladores dos conteúdos necessários para a formação e o trabalho profissional do assistente social e "desdobram-se em áreas de conhecimento que, por sua vez, se traduzem pedagogicamente através do conjunto dos componentes curriculares, rompendo, assim, com a visão formalista do currículo, antes reduzido a matérias e disciplinas" (ABEPSS/CEDEPSS, 1996, p. 63).
} 
maior diálogo entre docentes e, por consequência, uma articulação integral entre os fundamentos da formação, processos de trabalho e objeto do trabalho profissional. Neste mesmo sentido, está ocorrendo a construção da versão sete do currículo. Com maior diálogo institucional entre as áreas de conhecimento e com a inclusão de um currículo com muitos módulos comuns aos cursos de graduação da Instituição. Certamente este processo é carregado de inquietações e percalços que buscam garantir, no limite, a qualidade do processo formativo nos desafios do tempo presente.

Pontuamos, também, que o Curso de Serviço Social da Universidade de Santa Cruz do Sul é gradativamente avaliado pelo seu corpo docente e discente, tanto em reuniões do Núcleo Docente Estruturante, quanto pelo colegiado do Curso no qual, através da participação dos discentes, é possível desenvolver uma escuta qualificada e reflexiva das demandas que se apresentam para a formação profissional. Esses espaços vêm sinalizando a necessidade de instituir um diferencial para o Projeto Político Pedagógico do Curso cuja síntese vem sendo pensada e gestada por seu corpo docente e discente.

Realizados estes detalhamentos, seguimos abordando os campos de estágio presentes na história do Curso de Serviço Social da Unisc. Ao olharmos os primeiros relatórios de estágio dos estudantes nos arquivos do Curso, podemos notar que os primeiros campos de estágio foram: Gabinete de Assistência Judiciária da Unisc (GAJ/UNISC), Centros de Atenção Psicossocial, equipamentos da Política de Assistência Social, Programa de Erradicação do Trabalho Infantil de Rio Pardo, Oncocentro, Hospitais, Poder Judiciário, Centro Municipal de Atendimento à Sorologia (CEMAS), Presídios, Unimed, Abrigos, Associação Comunitária Pró-Amparo do Menor (COPAME) e KBH \& C TABACOS. Estes espaços socioocupacionais situavam-se nos locais de residência dos estudantes, como Santa Cruz do Sul, Venâncio Aires, Sobradinho, Vera Cruz, Candelária, Cachoeira do Sul, Encruzilhada do Sul, Sinimbu, Vale Verde, Vale do Sol, dentre outros espaços e municípios que fizeram parte desta história de maneira contínua.

Importante salientar que os campos de estágio são organizados a partir da realidade, interesse dos acadêmicos, bem como localidade dos mesmos. Portanto, em cada semestre, os campos de estágio se configuram a partir desta dinâmica. Atualmente o Curso conta com acadêmicos em estágio obrigatório no Hospital Santa Cruz, no CEMAS, na Secretaria de Políticas Públicas de Santa Cruz, no Centro de Referência da Assistência Social (CRAS), no Sindicato dos trabalhadores rurais, na Secretaria de Educação de Santa Cruz do Sul, e na Associação de Pais e Amigos de Santa Cruz do Sul (APAE) (segundo semestre de 2019). Conforme visualizamos no gráfico 2 deste estudo, o campo de estágio que o Curso teve maior 
inserção nesses 20 anos foi o da saúde, seguido do campo da assistência social e do campo sociojurídico.

Salientamos que o estágio curricular não obrigatório também se faz presente em toda história do Curso de Serviço Social da Unisc. Por meio de processos seletivos junto às prefeituras da região os acadêmicos encontram oportunidades de aprendizado e de aquisição de conhecimento de forma permanente em diferentes espaços de atuação profissional. Atualmente, o Curso conta com estudantes em estágio curricular não obrigatório na Secretaria Municipal de Políticas Públicas de Santa Cruz do Sul, na Secretaria Municipal de Saúde de Santa Cruz do Sul - Programa Infância Melhor (PIM) e na Secretaria Municipal de Habitação de Santa Cruz do Sul (segundo semestre de 2019).

Salientamos que o aprendizado do exercício profissional vivenciado através dos estágios curriculares obrigatórios vem ocorrendo a partir do quarto semestre do Curso e totalizam $15 \%$ de sua carga horária total. Na reformulação atual do currículo o estágio, no que se refere às horas em campo, terá um percentual de aproximadamente 19\% da carga horária total. Os estágios estão organizados de forma que os estudantes desenvolvam competências e habilidades durante os quatro semestres, com centralidade na observação, no planejamento, na execução e na avaliação, respectivamente.

Outro aspecto a ser destacado se refere ao Fórum de Supervisão que acompanha o processo de estágios no Curso desde sua gênese. Como forma de manter vivo e presente constantemente o diálogo com os campos de estágio, supervisores de campo, orientadores acadêmicos e estagiários, o Curso tem, como parte de seu planejamento anual, a realização de fóruns de supervisão. Estes são espaços de encontro, de aprendizado, de diálogo pedagógico e formativo e de construção coletiva do conhecimento atinente ao exercício profissional nos diferentes campos de atuação. Neles, é possível acompanhar de perto o processo de aprendizagem realizado pelos estudantes, bem como manter permanente vigilância quanto ao que preconiza a legislação e a política de estágios.

Seguimos, portanto, para a última parte deste texto, elucidando as contribuições do Curso no contexto regional em que o mesmo se insere, em especial às pesquisas e aos projetos de extensão já desenvolvidos.

\section{Contribuições do Curso de Serviço Social para o Contexto Local e Regional}

O profissional de Serviço Social, pelas características que envolvem seu processo de trabalho, requer um investimento na dimensão interventiva e investigativa, incondicionalmente. A dimensão investigativa é que determina a constituição de um 
profissional conhecedor do contexto onde atua, seja no âmbito do exercício profissional ou no âmbito da formação acadêmica. O lugar da dimensão investigativa na formação profissional tem significado uma construção permanente, uma vez que o objeto adotado para análise (Questão Social) requer, além de reflexões, estratégias para transformar-se em processos interventivos.

Esse exercício de conhecer o contexto implica reconhecer permanentemente um processo teórico-metodológico, ético-político e técnico-operativo a ser construído historicamente, base para a realização de investigações e, por conseguinte, para a atuação extensionista.

Salientamos que o Curso de Serviço Social, no âmbito da formação, integra o Programa de Residência Multiprofissional em Saúde (PRMS) desde a implantação, em 2014, oferecendo, anualmente, através do Ministério da Saúde, 02 bolsas para assistentes sociais. O Programa, orientado pelos princípios e diretrizes do Sistema Único de Saúde (SUS), com duração de dois anos, é desenvolvido nas dependências do HSC, da Universidade de Santa Cruz do Sul (Unisc), e em equipamentos da Secretaria Municipal de Saúde, parceira na sua implantação. Após ingresso no PRMS, a área de concentração de formação dos residentes é a de Atenção em Urgência e Emergência, configurando-se em ensino de pós-graduação Lato Sensu destinado a profissões relacionadas sob a forma de curso de especialização, caracterizado por ensino em serviço e sob orientação de profissionais altamente qualificados.

Com esta perspectiva de investigação constante e formativa, a partir de $2005^{3}$, o corpo docente do Curso de Serviço Social da Unisc desenvolveu, juntamente com estudantes na condição de bolsistas, um conjunto de projetos de pesquisa e de extensão de forma articulada com a graduação. O trabalho de pesquisa e extensão universitária realizado tem primado por parcerias com diferentes áreas do conhecimento, sendo o Serviço Social integrado de forma interdisciplinar. Entretanto, também ocorreram projetos em que docentes os desenvolveram na condição de coordenadores e, desta forma, produções científicas evidenciaram resultados de aprendizados coletivos e de parcerias consolidadas no contexto desta Universidade comunitária.

Em número de oito (8) foram as pesquisas coordenadas e executadas no âmbito do Curso de Serviço Social nestes quase vinte anos de existência. Entre as principais temáticas investigadas destacam-se as políticas de saúde, de educação e de assistência social. Também

\footnotetext{
${ }^{3}$ Computou-se os projetos de pesquisa e extensão universitária a partir de 2005 em virtude deste ano ter sido implantado um sistema informatizado denominado Workflow na Unisc. Cabe salientar que no período anterior ao mencionado, outros projetos de pesquisa e extensão universitária foram realizados, porém tivemos dificuldades para sistematizá-los em função da não informatização.
} 
se investigou as condições do mercado de trabalho e a inserção de egressos do Curso de Serviço Social da Unisc neste cenário.

Quadro 1: Pesquisas desenvolvidas no Curso de Serviço Social da UNISC

\begin{tabular}{|c|c|}
\hline Projetos de Pesquisa & Coordenadora(s) \\
\hline Direito universal: entre a concepção teórica e a provisão $(2006 / 2007)$ & Eunice Maria Viccari \\
\hline $\begin{array}{l}\text { Mapeamento da situação dos egressos do curso de Serviço Social da } \\
\text { UNISC em relação ao mercado de trabalho (2008) }\end{array}$ & $\begin{array}{l}\text { Mirian Neves Giglio da Silva } \\
\text { Eunice Maria Viccari }\end{array}$ \\
\hline $\begin{array}{l}\text { Monitoramento da representação da UNISC em espaços de } \\
\text { participação comunitária e de controle social (2009) }\end{array}$ & $\begin{array}{l}\text { Mirian Neves Giglio da Silva } \\
\text { Eunice Maria Viccari }\end{array}$ \\
\hline $\begin{array}{l}\text { Educação socialmente responsável em Universidades Comunitárias } \\
(2008 / 2009)\end{array}$ & Maira Meira Pinto \\
\hline $\begin{array}{l}\text { A situação de trabalho do egresso do curso de Serviço Social da } \\
\text { UNISC }(2012 / 2013)\end{array}$ & Mirian Neves Giglio da Silva \\
\hline $\begin{array}{l}\text { Trajetória de pessoas deficientes: a qualificação profissional e a } \\
\text { inclusão no mercado de trabalho no município de Santa Cruz do Sul } \\
(2013 / 2014)\end{array}$ & Eunice Maria Viccari \\
\hline $\begin{array}{l}\text { Construindo Tecnologia Assistiva a partir da história dos usuários do } \\
\text { Serviço de Reabilitação Física de Nível Intermediário - SRFis } \\
(2015 / 2016)\end{array}$ & Eunice Maria Viccari \\
\hline $\begin{array}{l}\text { Práticas de Trabalho Agrícola: comprometimento com relações de } \\
\text { trabalho seguras e justas. Realização de assessoria social para avaliar e } \\
\text { sensibilizar os produtores e seus trabalhadores quanto às condições } \\
\text { sociais dignas de subsistência e mudanças necessárias nas diferentes } \\
\text { realidades sociais (2019). }\end{array}$ & Marta von Dentz \\
\hline
\end{tabular}

Fonte: As autoras (2019)

De um modo geral as pesquisas realizadas por docentes do Curso de Serviço Social contemplaram aspectos referentes a Unisc, enquanto instituição comunitária e o seu papel junto à comunidade local e regional, bem como sua representação em espaços de controle social. Outras três pesquisas envolveram a temática da tecnologia assistiva, a trajetória de pessoas com deficiência e o direito universal. Outra pesquisa, iniciada em 2019, desenvolvida com o Núcleo de Pesquisa Social (NUPES), o Serviço Social coordena a área social no que tange a orientação a produtores e trabalhadores da cultura do tabaco.

A pesquisa "A situação de trabalho do egresso do curso de Serviço Social da UNISC" teve presente a totalidade de egressos do Curso de Serviço Social da Unisc graduados no período de dezembro de 2003 a fevereiro de 2011. Esse número representou 185 profissionais assistentes sociais. A relevância desta pesquisa está assentada em três aspectos: a aproximação do Curso de Serviço Social com a área da pesquisa acadêmica; a construção de 
conhecimento sob a realidade do trabalho profissional de assistentes sociais, área muito carente de estudos e informações; e o fato de poder adicionar a essa pesquisa, um novo conceito formalizado pela OIT - Organização Internacional do Trabalho, que é o do trabalho decente ${ }^{4}$.

Quadro 2: Projetos de extensão desenvolvidos no Curso de Serviço Social da Unisc

\begin{tabular}{|c|c|}
\hline Projetos de Extensão & Coordenação \\
\hline Projeto Semear Amigos (2005 a 2013) & $\begin{array}{l}\text { Edla Hoffmann, Maira Meira Pinto, Mirian } \\
\text { Luzia Giglio Neves Da Silva, Simone Ritta } \\
\text { Dos Santos, Rosane Bernadete Brochier Kist, } \\
\text { Tatiana Reidel }\end{array}$ \\
\hline Assessoria/Consultoria em políticas sociais (2005) & Simone Ritta dos Santos \\
\hline $\begin{array}{l}\text { Assessoria e consultoria na implantação e gestão em } \\
\text { projetos sociais (2006) }\end{array}$ & Simone Ritta dos Santos \\
\hline UNISC com a comunidade/bairro Bom Jesus (2005-2010) & $\begin{array}{l}\text { Maira Meira Pinto, Rosangela da Silva } \\
\text { Almeida, Cesar Hamilton Brito de Goes, } \\
\text { Edla Hoffmann. }\end{array}$ \\
\hline $\begin{array}{l}\text { Programa de capacitação continuada do corpo docente de } \\
\text { assistentes sociais do curso de Serviço Social (2005 e 2011). }\end{array}$ & $\begin{array}{l}\text { Maira Meira Pinto, Claudia Hochheim } \\
\text { Oliveira. }\end{array}$ \\
\hline $\begin{array}{l}\text { Proposta de assessoria pedagógica para a Escola Cristã de } \\
\text { educação política (ECEP) (2005) }\end{array}$ & Maira Meira Pinto \\
\hline Programa Inserção Comunitária (2010-2012) & Mirian Luzia Giglio Neves da Silva \\
\hline $\begin{array}{l}\text { Projeto de Trabalho Técnico-Social em Construção de } \\
\text { Unidades Habitacionais - Residenciais Santa Maria I e Mãe } \\
\text { de Deus (2019 a 2021). }\end{array}$ & Eunice Maria Viccari \\
\hline
\end{tabular}

Fonte: As autoras (2019)

No que se refere a projetos de extensão universitária, os temas que se destacaram em oito (8) projetos coordenados foram: assessoria a políticas sociais, trabalho comunitário com jovens, trabalho e convivência em comunidade, trabalho comunitário em âmbito habitacional,

\footnotetext{
${ }^{4} \mathrm{O}$ conceito de trabalho decente expressa a missão histórica de promover oportunidades para que homens e mulheres obtenham um trabalho produtivo e de qualidade, em condições de liberdade, equidade, segurança e dignidade humanas, sendo considerado condição fundamental para a superação da pobreza, a redução das desigualdades sociais, a garantia da governabilidade democrática e o desenvolvimento sustentável conforme cunhado pela OIT.
} 
convivência com crianças e adolescentes e inserção comunitária da Universidade nas escolas da região.

Um projeto de extensão importante que fez parte da história do curso foi o Semear Amigos (PSA). O projeto, desenvolvido pela Unisc, em parceria com a empresa PIONEER, desde sua criação, em outubro de 2005, foi coordenado por docente do Curso de Serviço Social. O mesmo ocorria na Escola Estadual Nossa Senhora da Esperança, no Bairro Santa Vitória, em Santa Cruz do Sul, com uma equipe interdisciplinar integrada por profissionais das áreas do Serviço Social, da Psicologia, da Informática, da Educação Física, da Música e de profissionais da área da Educação (Pedagogia). As ações do PSA privilegiavam o atendimento individual e grupal de crianças, adolescentes e de seus respectivos familiares, moradores do Bairro Santa Vitória em seus últimos anos, que, em sua grande maioria, vivenciam situações de vulnerabilidade social. Buscava-se, também, através de parcerias com a Escola Estadual Nossa Senhora da Esperança, com as lideranças comunitárias e com a rede socioassistencial do Município garantir que as crianças e os adolescentes recebessem proteção social e seus direitos assegurados, compreendendo, também, seus deveres como cidadãos. O mesmo foi finalizado devido a ausência da continuidade de financiamento pela empresa envolvida.

Outro projeto de extensão bastante significativo, também coordenado por docentes do Curso, foi o desenvolvido no Bairro Bom Jesus, em Santa Cruz do Sul. Durante quatro anos foi desenvolvido um trabalho de caráter comunitário no Bairro referido, que envolveu a totalidade de seus moradores através de atividades com crianças, adolescentes, mulheres, idosos e associação de moradores. O Projeto contou com a participação de diversos parceiros em suas diferentes edições, tais como Curso de Letras, Curso de Odontologia, Orquestra, todos vinculados à Unisc. Também teve a participação de estudantes bolsistas de extensão, o que trouxe grande enriquecimento para as atividades propostas no Projeto.

Atualmente, o Curso conta com projeto de extensão no Serviço de Reabilitação Física Nível Intermediário - Professora Eunice Maria Viccari. O "Serviço de Reabilitação Física Nível Intermediário" articula a área da Formação e Atenção em Saúde juntamente com professores e estudantes dos cursos de Serviço Social, fisioterapia, psicologia, nutrição, enfermagem e medicina. O objetivo do Serviço é programar e executar um projeto terapêutico individual acompanhando os usuários amputados e portadores de necessidades especiais, bem como seus familiares e cuidadores, numa perspectiva de atenção integral em saúde. Este Serviço de Reabilitação funciona através do convênio firmado com o Ministério da Saúde para o processo de reabilitação e com a Secretaria Estadual da Saúde para Dispensação de 
Órteses e Próteses de Saúde, atribuindo-lhe um caráter de referência para os municípios da Região dos Vales do Estado do Rio Grande do Sul. Assim, Formação e Atenção a Saúde se materializam em dois eixos que permitem possibilidades de reflexões e discussões em equipe, contribuindo com a formação dos estudantes numa perspectiva de trabalho interdisciplinar com atendimento e atenção integral à saúde dos usuários.

$\mathrm{Na}$ dimensão extensão universitária, portanto, os docentes vêm se envolvendo em diferentes capacitações, possibilitando campos de trabalho para assistentes sociais e para outros trabalhadores de políticas sociais da área de abrangência da Unisc e, igualmente, de estudantes que vem desenvolvendo competências e habilidades complementares importantes e necessárias a sua formação.

Sumariamente, podemos reiterar que os projetos de pesquisa, de extensão, bem como os projetos de intervenção e os Trabalhos de Conclusão de Curso mencionados neste artigo, conjuntamente, refletem e impactam na realidade social da região de abrangência da Unisc. Com diferentes potencialidades, todos os elementos citados produzem um efeito e uma intervenção em diferentes realidades sociais. De modo que as contribuições do Curso de Serviço Social na região possuem uma identidade acadêmico-científica importante de ser recordada e continuada, uma vez que incidem diretamente na garantia de direitos para tantos seres humanos que fizeram e fazem parte desta história.

\section{Considerações finais}

Escrever sobre um Curso que faz parte da nossa própria história não é tarefa fácil. Ao mesmo tempo, é imensamente prazeroso resgatarmos aspectos importantes de um Curso que vem se redimensionando constantemente, tendo em vista as ininterruptas mudanças na vida social e no mundo do trabalho. A intenção deste artigo, portanto, foi de desenhar a gênese, o desenvolvimento, a continuidade e permanência do Curso de Serviço Social nestes quase vinte anos de existência, sem deixar de mencionar elementos fundamentais nesta trajetória, a saber: principais desafios, profissionais formados pelo Curso, pesquisas de Trabalho de Conclusão de Curso, docentes envolvidos Projetos Político Pedagógicos, contribuições do Curso de Serviço Social para o contexto regional em que está inserido com base nos projetos de extensão e nas pesquisas coordenadas por docentes do Curso.

Cabe considerar que, a responsabilidade com a formação de profissionais do Serviço Social no cenário do ensino superior, vem se tornando cada vez mais instigante e complexificada tendo em vista as mudanças que vêm ocorrendo na própria lógica de pensar e operacionalizar a formação superior no Brasil. Nesta perspectiva, o trabalho desenvolvido 
pelos docentes do Curso de Serviço Social busca acompanhar estas mudanças, sem perder de vista aquilo que nos é mais caro - o perfil de profissionais assistentes sociais que temos a responsabilidade de graduar.

Este perfil nos acompanha a cada reflexão, a cada mudança proposta, de modo a resguardar características que são essenciais a um assistente social competente e qualificado. Tais características levam em consideração a identificação das demandas presentes na sociedade, visando a formular respostas profissionais para o enfrentamento da questão social; comprometimento com a perspectiva de transformação da realidade social dos sujeitos de direitos; assistentes sociais propositivos, questionadores e formuladores de planos, programas e projetos que subsidiem e dinamizem qualificadamente as políticas sociais, organizações da sociedade civil, bem como diversos espaços sócio ocupacionais da categoria profissional.

Outrossim, o aprimoramento de competências necessárias a um assistente social é desafio diário na história do Serviço Social da Unisc. Permeado de incertezas e desafios, mas também de vontade e competência de um corpo docente qualificado e comprometido com a formação de assistentes sociais na área de abrangência da Unisc. Essas competências são preconizadas nas próprias Diretrizes Curriculares da área, dentre as quais: elaboração, execução e avaliação de planos, programas e projetos na área social; desenvolvimento de metodologias que favoreçam processos participativos e socioeducativos com a população usuária das políticas sociais; realização de pesquisas que subsidiem a formulação de políticas e ações profissionais; prestação de assessoria e consultoria a órgãos da administração pública, empresas privadas e movimentos sociais em matéria relacionada às políticas sociais e à garantia de direitos civis, políticos e sociais da população; realização de visitas, perícias técnicas, laudos, estudos socioeconômicos e pareceres sobre matéria de Serviço Social e, supervisão direta de estagiários de Serviço Social.

Ao in (concluir), então, esta reconstrução histórica do Curso, consideramos que a contribuição do Curso para a Instituição Comunitária, para a comunidade local e regional, para os acadêmicos em formação, para os mais de 290 egressos do Curso é, sem dúvida, ímpar e relevante para a própria história da Unisc e da comunidade local e regional. Nosso desejo é que esta história continue e permaneça gerando bons frutos e qualificando ainda mais o cenário social, comunitário e do trabalho social da região. 


\title{
SOCIAL SERVICE AT THE COMMUNITY UNIVERSITY OF SANTA CRUZ DO SUL: HISTORICAL AND CURRENT ASPECTS OF FORMATION
}

\begin{abstract}
This article presents the history of the Social Work Course from Unisc, which is about to celebrate its twenty years of existence, on top of weaving articulations with the formation in Social Work in contemporary times. In this sense, to build an approach on the formative historicity of Social Work in this higher education institution, it

implies a deepening of what Social Work has accumulated in trajectory, experience, weaving articulations about the formation in Social Work. To this end, we organized this itinerary into three moments: first, we seek to mobilize the memory from which the current moment of the Unisc's Social Work Course is heir, emphasizing its historical path, its genesis, its challenges, the professionals graduated from the course, the researches for the Completion of the course Essays, the teachers involved in this journey of almost two decades; as a second emphasis, we focused on training, on the Pedagogical Political Projects that were part of this history and the internship fields; and finally as a third element, we reasoning about the contributions of the Social Work. Course to the regional context in which it is inserted based on extension projects and researches made. As synthetizations, this article reiterates the different contributions from the Social Work Course during twenty years at local and regional level through the training in Social Work of innumerous academicians, intervention projects, researches, extension projects that directly affected the different social realities.
\end{abstract}

Keywords: Social Work; Higher education; Formation.

\section{REFERÊNCIAS}

ABEPSS. Política Nacional de Estágio da Associação Brasileira de Ensino e Pesquisa em Serviço Social (ABEPSS), 2010.

Diretrizes Curriculares da Associação Brasileira de Ensino e Pesquisa em Serviço Social - ABEPSS de 1999.

ABESS/CEDEPSS. Caderno ABESS n. 07. Caderno Especial: Formação Profissional: trajetórias e desafios. Cortez, São Paulo: 1996.

BRASIL. Lei $n^{\circ} 8.662 / 93$ que dispõe sobre a Profissão de Assistente Social, 1993.

CASTEL, Robert. As metamorfoses da questão social: uma crônica do salário. Tradução Iraci D. Poleti. Petrópolis: Vozes, 1998.

CFESS. Código de Ética do Assistente Social. Brasília: CFESS, 1993.

DENTZ, Marta von. O ensino superior em Serviço Social no início do século XXI: um olhar desde a sociedade do espetáculo. Barbarói, Santa Cruz do Sul, n.51, p.<73-89>, jan/jun, 2017.

IAMAMOTO, Marilda Villela. 80 anos do Serviço Social no Brasil: a certeza na frente, a história na mão. Serv. Soc. Soc., São Paulo, n. 128, p. 13-38, jan./abr. 2017.

; CARVALHO, Raul. Relações Sociais e Serviço Social no Brasil: esboço de uma interpretação histórico-metodológica. São Paulo, Cortez, 1983.

Barbarói, Santa Cruz do Sul, n.59 - número especial, p.<194-212>, Ago./Set. 2021 
MEC/CNE. Resolução CNE/CES. $n^{\circ}$ 2, de 18 de julho de 2007. Dispõe sobre carga horária mínima e procedimentos relativos à integralização e duração dos cursos de graduação, bacharelados, na modalidade presencial, 2007.

. Diretrizes Curriculares para os Cursos de Serviço Social. Resolução $n^{\circ} 15$ de 13 de março de 2002. Câmara de Educação Superior/CES, 2002.

PEREIRA, Larissa Dahmer. Mercantilização do ensino superior, educação à distância e Serviço Social. Rev. Katál. Florianópolis v. 12 n. 2 p. 268-277 jul./dez. 2009.

UNISC. Projeto Político Pedagógico do Curso de Serviço Social, 2018.

\section{Sobre as autoras:}

Eunice Maria Viccari é Assistente Social; docente do Curso de Serviço Social da Universidade de Santa Cruz do Sul; Graduada em Serviço Social pela Fundação Educacional do Alto do Vale do Rio do Peixe (1981); Mestre e Doutora em Serviço Social pela Pontifícia Universidade Católica do Rio Grande do Sul (2001 e 2008, respectivamente).

Maira Meira Pinto é Assistente Social; docente do Curso de Serviço Social da Universidade de Santa Cruz do Sul; Graduada em Serviço Social (2000); Mestre em Serviço Social (2002); Doutora em Educação (2009) pela Pontifícia Universidade Católica do Rio Grande do Sul.

Marta von Dentz é Assistente Social; docente do Curso de Serviço Social da Universidade de Santa Cruz do Sul; Graduada em Serviço Social pela Universidade do Oeste de Santa Catarina (2013); Mestre em Educação pela Universidade Federal da Fronteira Sul (2015); Doutora em Serviço Social pela Pontifícia Universidade Católica do Rio Grande do Sul (2019). 